\title{
A bioeconomy perspective for natural sweetener Stevia
}

\author{
Rosaria Ciriminna, ${ }^{1}$ Francesco Meneguzzo, ${ }^{2}$ Mario Pecoraino, ${ }^{3}$ Mario Pagliaro*1 \\ ${ }^{1}$ Istituto per lo Studio dei Materiali Nanostrutturati, CNR, via U. La Malfa 153, 90146 Palermo, Italy, mario.pagliaro@cnr.it \\ ${ }^{2}$ Istituto di Biometeorologia, CNR, via G. Caproni 8, 50145 Firenze, Italy \\ ${ }^{3}$ via C. Giaquinto 14, 90135 Palermo, Italy
}

\begin{tabular}{|c|c|}
\hline & ABSTRACT \\
\hline $\begin{array}{l}\text { Keywords: } \\
\text { Stevia rebaudiana } \\
\text { Sweetener } \\
\text { Bioeconomy } \\
\text { Stevioside } \\
\text { Rebaudioside } \\
\text { Steviol }\end{array}$ & $\begin{array}{l}\text { The "sweet herb" (El Caa-ehe) used by the Guaraní tribes living in the forests of today's eastern } \\
\text { Paraguay and southern Brazil, is rapidly emerging as natural sweetener alternative both to sugar } \\
\text { and synthetic sweeteners, well beyond Japan where it is widely used since the mid 1970s. Stevia } \\
\text { rebaudiana (Bertoni) Bertoni contains in its leaves highly sweet steviol glycosides which do not } \\
\text { release calories in the human body and do not cause an increase in blood sugar levels. The } \\
\text { glycoside most abundant in the leaves, stevioside, has high reactive oxygen species quenching } \\
\text { activity originating several health beneficial properties. Rapid advances in green chemistry } \\
\text { technology allowing the production of Stevia extracts devoid of liquorice-like after-taste, and } \\
\text { their high chemical and physical stability enabling use in baked and beverage food products } \\
\text { support large scale uptake of Stevia as natural sweetener. Addressing bioeconomy aspects } \\
\text { ranging from production through product formulation, this study identifies the last obstacles to } \\
\text { overcome prior to general adoption of } S \text {. rebadudiana as health beneficial sweetener. }\end{array}$ \\
\hline
\end{tabular}

\section{Introduction}

Named by naturalist Moisés Santiago Bertoni after botanist and physician Pedro Jaime Esteve who first described the plant found in eastern Paraguay in mid $16^{\text {th }}$ century, and also incorporating the name of Paraguayan chemist Ovidio Rebaudi who in 1899 conducted the first chemical analyses aimed to clarify the origin of the sweet taste upon request of Bertoni, ${ }^{1}$ Stevia rebaudiana Bertoni (Bertoni) has rapidly become the main natural sweetener used across the world. In 2017, the number of new food and beverage products using Stevia's extracts outpaced those using synthetic sweetener aspartame. ${ }^{2}$

The plant's leaves, indeed, contain glycosides of the diterpene steviol (ent-13-hydroxykaur- 16-en-19-oic acid) such as stevioside and rebaudiosides A which are up to 400 times sweeter than sucrose (sugar), releasing almost no calories in the body and not affecting blood sugar levels, thereby helping in calorie reduction. The glycosides, furthermore, do not undergo fermentation in the mouth thus causing no tooth attack and cavity formation. ${ }^{3}$

Steviol glycosides were first successfully commercialized in Japan in 1971 . $^{4}$ Their approval in the rest of the world is quite recent, having been approved in 2008 in the US and in 2011 in the EU (as high-purity stevia leaf extract labelled E 960). Today Stevia's extracts are approved for use in food and beverage products in most world's countries including large nations such as Russia, China, India, Canada and Brazil.
In the European Union steviol glycosides are also approved as a dietary supplement with an acceptable daily intake of 4 $\mathrm{mg}$ of steviol (steviol glycosides) per $\mathrm{kg}$ of body weight ${ }^{5}$ identical to the intake recommended by the WHO's Joint Experts Committee on Food Additives.

Following a burst of new studies which in the late 1990s, clarified its agricultural, ${ }^{6}$ biological, and chemical properties, numerous recent studies address the use of Stevia rebaudiana purified extract as zero-calorie sweetener, ${ }^{7}$ as a sweetener in pediatric oral formulations, ${ }^{8}$ and its future potential. ${ }^{9}$

We will not deal with the health and safety aspects of Stevia's utilizazion since, as put it by Talevi, "an enormous body of preclinical evidence demonstrates the great pharmacological potential of Stevia rebaudiana (Bertoni) and its crude and purified extracts". ${ }^{3}$ Stevioside, for instance, actively counteracts high blood pressure, type 2 diabetes, arteriosclerosis and some forms of cancer due to its strong ability to scavenge reactive oxygen species, and hydroxyl and superoxide radicals in particular. ${ }^{10}$

The negative results in toxicity trials subsequently used by regulating authorities of other countries largely originate by tests carried out by Japanese scholars both on Stevia extracts or single steviol glycosides during their evaluation of stevia as a possible sweetening agent in the 1970 s. ${ }^{11,12}$

In general, the safety of consumption of both Stevia integral extracts and high-purity steviol glycosides at or below the acceptable daily intake is nowadays well established. Interested readers are referred to Geuns' 2012 account on 
safety evaluation of Stevia and stevioside ${ }^{13}$ as well as to the recent comprehensive analysis of Talevi. ${ }^{3}$

This study offers a bioeconomy perpsective on this prominent natural sweetener. International research projects financed with the aim to diversify with stevia the cultivation of tobacco farmers,${ }^{14}$ new trade associations, ${ }^{15}$ new international conferences $^{16}$ and a global market boom ${ }^{2}$ testify to the undergoing global uptake of steviol glycosides as the favoured sweetener of the near future.

In Europe steviol glycosides are classified as food additives (E 960), and thus their use as a food sweetener (and not a natural product) is regulated under the European Parliament and Council Regulation (EC) No 1333/2008 on food additives, and the only ingredient usable is steviol glycosides purified at $95 \%$. Yet, the global demand for Stevia is part of the overall demand for "naturals" is a megatrend (a global macroeconomic force originating in culture and society impacting business and the economy) which is driving the accelerated adoption of natural products replacing synthetic functional products in almost all segments of the food, cosmetic and personal care industries. $^{17}$

Addressing bioeconomy aspects ranging from production through product formulation, this study identifies the last obstacles to overcome prior to general adoption of $S$. rebadudiana as healthy sweetener alternative both to synthetic sweeteners and to sugar.

\section{Composition, analysis and extraction routes}

The main steviol glycosides imparting the leaves of Stevia rebaudiana with sweet taste are stevioside $(5-10 \% \mathrm{w} / \mathrm{w}$ on a dry weight basis), rebaudiosides $\mathrm{A}(2-5 \%)$ and $\mathrm{C}(1 \%)$, dulcoside A $(0.5 \%)$, rebaudiosides $\mathrm{D}, \mathrm{E}$, and $\mathrm{F}(0.2 \%)$, and steviolbioside $(0.1 \%){ }^{18}$ The overall number of ent-kaurane diterpenoid glycosides identified in trace amount was 34 as of April 2013, ${ }^{18}$ and now exceeds the 40 threshold, including rebaudioside $\mathrm{M}$, a compound with a clean, sweet taste and moderate licorice aftertaste abundant in a $S$. rebaudiana plant cultivar resulting from a controlled breeding program or from recombinant microorganisms which was approved by the European Food Safety Authority (EFSA) Panel on Food Additives and Nutrient Sources added to Food provides. ${ }^{19}$

Stevioside was first isolated in France by Bridel and Lavieille in $1931,{ }^{20}$ whereas the structure and stereochemistry of the steviol aglycon, as well as the highly stable isosteviol formed upon acid treatment of steviol via Wagner-Meerwein rearrangement, was actually identified in $1960 .^{21}$

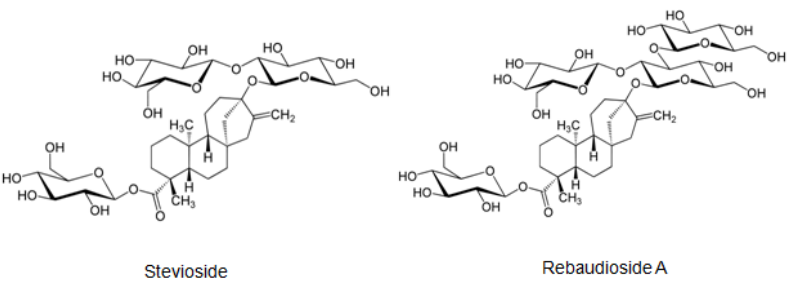

Figure 1. Stevioside and Rebaudioside A, molecular structures.

The content of the two major steviol glycosides, stevioside (ST, Figure 1) and rebaudioside A (Reb A, Figure 1) is measured using HPLC liquid chromatography according to a standard procedure recommended by the Joint FAO WHO Expert Committee on Food Additives in 2010.
The method typically requires $25 \mathrm{~min}$ to determine the weight percentage of seven steviol glycosides (stevioside, rubusoside, dulcoside $\mathrm{A}$, steviolbioside, rebaudioside $\mathrm{C}$, rebaudioside $\mathrm{B}$, and rebaudioside $\mathrm{A}$ ) by $\mathrm{UV}$ detection at 210 $\mathrm{nm}$ using $80 / 20$ acetonitrile/water at $\mathrm{pH}=3.0$, adjusted with phosphoric acid. ${ }^{22}$

More recently, Zimmermann in Germany has achieved the separation of nine steviol glycosides using a faster ultra-high performance liquid chromatography (UHPLC) method reducing to $11 \mathrm{~min}$ the overall separation time for 9 steviol glycosides, proposing the method to undergo multi-laboratory validation in order to prove its suitability as new official method. ${ }^{23}$

Similarly, McChesney and co-workers have lately developed a chromatographic method using acetonitrile:water to separate and analyze fractions rich in very polar steviol glycosides. ${ }^{24}$ In general, the higher the Reb A and ST glycoside content in the dried leaves, the higher is the price paid to farmers by the Stevia processing companies. The optimum harvest date coincides with the bud-flowering stage at the beginning of September. ${ }^{25}$

Numerous agricultural efforts are aimed at improving steviol glycosides in leaf tissues, preferably avoiding gene manipulation as consumers looking for naturals are interested in GMO-free Stevia. From microwave-assisted extraction to rapid solid-liquid dynamic extraction, several new technologies for the recovery of phytochemicals from Stevia's leaves have been investigated. ${ }^{26}$

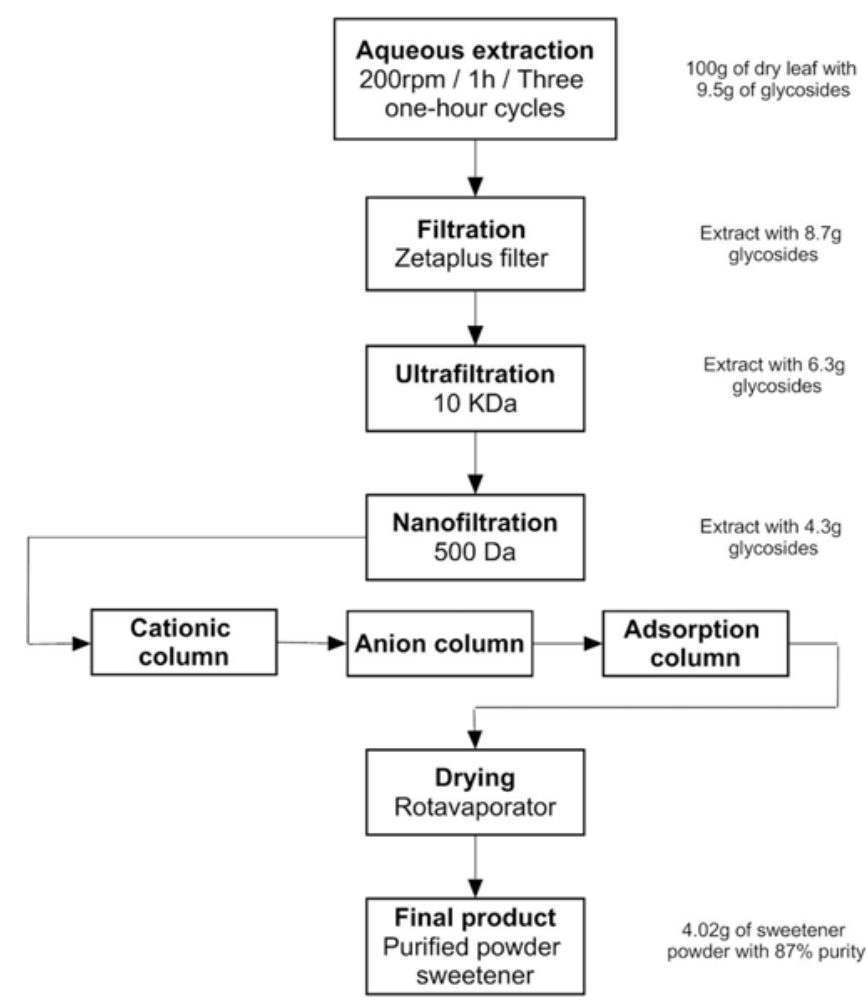

Figure 2. Flowchart for obtaining the enhanced sweetener powder from the leaves of $S$. Rebaudiana after preliminary treatment with absolute ethanol. [Reproduced from Ref. 27, with kind permission].

Recently scholars in Brazil demonstrated how a simple pretreatment of the leaves of $S$. rebaudiana with a high content of rebaudioside A with absolute ethanol increases the yield and purity level of stevia sweetener, significanly enhancing also 
the sensory characteristics of the steviol glycoside extract. ${ }^{27}$ In brief, the treatment of stevia leaves with ethanol before the extraction process of steviol glycosides selectively removes substances such as phenolic compounds and flavonoids, which contribute to the residual bitter taste in the final product.

The extraction conditions of aqueous extraction of steviol glycosides (Figure 2) were optimized via response surface methodology. Eventually, the $S$. rebaudiana leaves were extracted with water $\left(1: 27, \mathrm{w} / \mathrm{v}\right.$ at $60^{\circ} \mathrm{C}$ and $200 \mathrm{rpm}$ in three cycles). Then, the crude extract was filtered under a vacuum to remove the suspended particles. For purification, the filtered crude extract passed through UF (10 kDa) and NF (500 Da) membranes with an ion exchange and adsorption column eluting with ethanol:water $(85: 15, \mathrm{v} / \mathrm{v})$. The purified sweetener in powder form was obtained via simple rotary evaporation.

An increase of $43 \%$ in yield of steviol glycosides was obtained from treated leaves (recovery went from $2.20 \mathrm{~g}$ for in natural leaves to $4.02 \mathrm{~g}$ for pretreated leaves), with a respective level of purity of $87 \%$ and $84.8 \%$. Remarkably from the point of view of final use of the extract as natural sweetener, the scholars found that the antioxidant activity, phenolic compounds and flavonoids increased, whereas arachidic and beenic fatty acids were detected only in the leaves treated with EtOH. Furthermore, sensorial evaluation demonstrated that the extract from pretreated leaves presented a sensory profile similar to that of synthetic sweetener sucralose, a chlorinated sugar, with the acceptance of the sweetener consumed by the treated leaves $(7.00 \pm 1.95)$ even higher than that of the world's most used synthetic sweetener $(6.33 \pm 1.72){ }^{27}$

In detail, the sweetener obtained was 165 times sweeter than sucrose, and the bitterness threshold was $0.073 \pm 0.013 \mathrm{~g} / 100$ $\mathrm{mL}$, considerably higher than the threshold of bitterness of stevioside $(0.0172 \pm 0.0050 \mathrm{~g} / 100 \mathrm{~mL})$ and stevioside enzymatically modified $(0.0263 \pm 0.0056 \mathrm{~g} / 100 \mathrm{~mL})$, therefore proving to be significantly less bitter.

On the other hand, the ethanolic extract included several compounds that present a dramatic utilization potential in food, beverage, nutraceutical, cosmetic and personal care products. The ethanolic extract, indeed, showed high antioxidant potential and 39 compounds were identified, by UPLC/HRMS.

Mass spectrometry investigation of the Stevia extracts shows that centaureidin, epigallocatechin gallate, coumaric, caffeic, coumaroylquinic and chlorogenic acids are the most abundant phenol antioxidants. These compounds include flavonoid derivatives (quercetin, centaureidin, epigallocatechin gallate, luteolin-glucoside) and hydroxycinnamic acids (coumaric, caffeic, chlorogenic and coumaroylquinic acids). ${ }^{28}$

These extracts, rich in flavonoids and hydroxycinnamic acids, have strong reducing properties. For example, they readily reduce $\mathrm{Ag}^{+}$in solution affording silver nanoparticles of spherical shape with $16-25 \mathrm{~nm}$ average sizes in a truly green synthesis of metal nanoparticles which is of great practical relevanc in today's industrial context in which metal nanoparticles find a large and ever increasing number of applications. $^{28}$

$$
\begin{aligned}
& \mathrm{R}-\mathrm{OH} \rightarrow \mathrm{R}-\mathrm{O}^{-}+\mathrm{H}^{+} \\
& \mathrm{R}-\mathrm{O}^{-} \rightarrow \mathrm{R}-\mathrm{O}^{\cdot}+\mathrm{e}^{-}
\end{aligned}
$$

Electrons are made available via the dissociation of hydroxyl group of phenol compounds (Eq. 1) and subsequent detachment of electron from $\mathrm{R}-\mathrm{O}^{-}$anion (Eq. 2), as the energy of electron transfer from deprotonated molecule is significantly lower than that required for hydrogen or electron detachment from the whole molecule. ${ }^{28}$

\section{Uses, market, and perspective}

Sweeteners from Stevia extracts, available on the marketplace in powder, tablet and liquid form, today are widely used to sweeten a variety of beverage and food products. $^{7}$ Steviol glycosides, indeed, display remarkable physical and chemical stability allowing their use in acidic beverages as well as in cooked foodstuff from biscuits and bakery goods, dressings and sauces, frozen foods, processed fruits and vegetables, snacks and cereals. In personal care products, Stevia-based extracts are used in toothpaste and mouthwash formulations replacing saccharin and older synthetic sweeteners and offering further purifying action.

As mentioned above, innovation efforts in agriculture have led to optimal varietal selection with the objective to select plants with the best organoleptic result, preferably without the use of enzymes or genetically modified plants. Variants of the Stevia plant producing more glycosides than others are selected as cultivars further optimizing the cultivation conditions to optimally grow the plant in different climates.

Forecasts dating back to 2013 for which Stevia would be "unlikely to widely replace other high intensity sweeteners in the medium term,"29 turned out to be inaccurate. As mentioned above, in 2017 the number of new commercial products sweetened with steviol glycosides outpaced those using aspartame. $^{2}$

As it happens with pectin, another natural product in great demand, ${ }^{30}$ figures concerning the market size and estimates about its growth greatly differ. According to one reputed market intelligence company, the global stevia market generated \$338 million in 2015 and was anticipated to grow to $\$ 554$ million by 2024 (at $6.1 \%$ compound annual growth rate). ${ }^{31}$

According to another analyst the global Stevia market generated \$417 million revenues in 2017 and was forecasted to value $\$ 721$ million by the end of 2024 , growing at $8.2 \%$ annual rate. ${ }^{32}$ Finally, another market intelligence company estimates that, based on current trends which saw between 2011 and 2016 the market launch of over 14,000 food and beverage products with Stevia across the world, ${ }^{33}$ the global market should exceed $\$ 1$ billion by $2021 .^{34}$

Currently, S. rebaudiana is mainly cultivated in China, Japan, Malaysia, Indonesia, Thailand, and Armenia, in Asia, and in Kenya, Ghana, Rwanda, Morocco, Zambia, Tanzania and Congo in Africa. Cultivation in large and sunny countries such as India, Turkey, Mexico and the U.S., is currently being rapidly expanded.

In Turkey, for example, by mid 2017 dried Stevia leaves obtained from cultivation of the plant in a wet area where it is harvested twice a year, were sold at $\$ 150 / \mathrm{kg}{ }^{35}$ Since in that farm one hectare affords $123 \mathrm{~kg}$ of the end product, revenues for the farming company in that area of Turkey were exceeding $\$ 18,400$ per hectare.

It is instructive to review the market prices in the last decade, namely the first of the Stevia era as a global sweetener. In the U.S., on the basis of the favorable review by the Joint FAO WHO Expert Committee on Food Additives in Europe, ${ }^{36}$ 
several food and beverage products by different manufacturers were affirmed with GRAS status, ${ }^{37}$ and the production of Stevia purified extracts quickly went from 5,000 tonnes in 2008 to over 20,000 tonnes in $2011 .^{38}$ This caused overcapacity as demand was growing at slower pace.

In 2013 the prices of Reb A 95\% pure (Reb A 95) in China started to decline from over $\$ 110,000 / t$ to less than $\$ 99,000 / t$ by early 2014 , recovering since the beginning of 2014 , due to the scaling down of production by Chinese suppliers leading a reputed market analyst to argue that "the price of stevia was already high compared to other sweeteners, and these new increases could be limiting the expansion of the industry". 39

However, in the subsequent three years the continuing growth of new products containing S. Rebaudiana extracts further boosted production, and the price of one tonne of Reb A 95 went from $\$ 122,000$ In January 2015 to to $\$ 73,000$ in July of that year. ${ }^{39}$ Almost two years later, by February 2017, prices of Reb A 95 were almost unvaried to $\$ 77,300$ per tonne. ${ }^{39}$

Three years before, a thorough market study conducted in Malaysia aimed to investigate factors that influence the acceptance of Stevia-based products by consumers, had revealed that most of the respondents were willing to use Stevia-based products as a substitute for sugar. ${ }^{40}$ Consumers with higher level of education showed more willingness to change for Stevia-based products based on health benefits, leading the team to conclude that an effective promotion was necessary to increase consumer's awareness toward a more healthy diet. ${ }^{40}$

\section{Conclusions and recommendations}

In the safety review of Stevia that in 1992 accompanied a GRAS affirmation petition Douglas Kinghorn wrote: "the vast majority of the scientific safety evaluation studies which have been performed to date endorse the use of Stevia rebaudiana leaf and stevioside as sucrose substitutes. This is substantiated by the extensive use in Japan of these products without a single adverse report to date". ${ }^{41}$

Since then, the use of $S$. rebaudiana as sweetener as extended to almost all the world's countries with many new health beneficial effects having been discovered. Four main recommendations emerge from this bioeconomy study.

First, the use of Stevia as natural sweetener as alternative to artificial sweeteners should focus on this consumer's desire to achieve outcomes such as better health, lower weight, and slower aging. Remarking how "consumers can be provided with the best nutritional knowledge and palatable wellbalanced food options and still make choices that are not good for their physical health" de la Peña has noted how in the history of artificial sweeteners adoption in the US "the many failures of nutrition education in the $20^{\text {th }}$ century suggest that we are missing something important in how we think about the relationship between consumer desire and healthy food consumption...as these foods promise to deliver more than fullness. They promise that through their ingestion we will become more of what we desire to be". 42

Second, companies trying to promote the adoption of Stevia as universal sweetener will benefit from learning the approach chosen by a consortium of four companies in France, including Europe's leading manufacturer of purified steviol glycosides. ${ }^{43}$
Aware that industrial customers have been accustomed to formulate with artificial sweeteners since several decades, the France-based consortium offers perspective customers the unique expertise of one of its partnering company to guide customers on how to formulate food and beverage products with steviol glycosides.

Third, Stevia's stakeholders and companies operating in their national markets should learn from what the Stevia Konwakai (today renamed Stevia Kogyokai) Japan's Stevia industrial consortium has done to promote the uptake of stevia sweeteners (first mixed with licorice-derived glycyrrhizin and later on with "rebaudioside A-enriched stevia extract") after the ban on dulcin and cyclamate in Japan in $1969 .^{44}$ This was achieved not only through collaborative work in obtaining permission and registration of Stevia as a sucrose substitute, but also through the exchange of information on production, marketing, and research. ${ }^{44}$

Fourth, noting that misconceptions surrounding Stevia continue to slow progress in its uptake minimising the incidence of diabetes and obesity, ${ }^{45}$ practitioners of the bioeconomy should be aware that progress in formulating sweeteners based on steviol glycosides has been so significant that today children prefer skim chocolate sweetened with a commercial Stevia sweetener white powder soluble in water produced from aqueous extract of Stevia leaves $(95 \%$ on dry weight basis in steviol glycosides, Rebaudioside A plus Stevioside $>75 \%)^{46}$

As lately shown by Formigoni and co-workers in Brazil, ${ }^{27}$ a simple treatment of the Stevia leaves with absolute ethanol before the aqueous extraction of steviol glycosides selectively removes the phenolic compounds and flavonoids which contribute to the residual bitter taste in the final product affording steviol glycosides whose sensory profile is similar (and better) to that of sucralose.

Fifth, when substituted for sugar, Stevia can be used by anyone, including normal-weight persons aiming to reduce overall sugar intake and improve dietary quality. ${ }^{47}$ Hence, forward looking companies would avoid to use Stevia in combination with sugar or with artificial sweeteners but would rather formulate natural Stevia's extracts with natural bulking and hydrocolloid agents such as pectin or natural dietary fibre. ${ }^{48}$

Eventually, due to the rising health concerns among people on the role of sugar consumption in the global epidemics of obesity and type 2 diabetes, ${ }^{49}$ Stevia will not only compete with artificial high-intensity sweeteners, but also directly with sugar (sucrose) and high-fructose corn syrup.

\section{Acknowledgments}

This study is dedicated to Professor Jan Geuns, Katholieke Universiteit Leuven, for all he has done to develop the science and chemistry of Stevia rebaudiana for the benefit of mankind.

\section{References}

1. M. S. Bertoni, El Caa-ehe (Eupatorium rebaudianum, species nova), Rev. Agr., Ascunion 1899, 1, 35-37.

2. E. Watson, Stevia outshines aspartame as high intensity sweetener of choice in global new product launches in 2017, FoodNavigator-USA, 30 March 2018. www.foodnavigatorusa.com/Article/2018/03/30/Stevia-outshines-aspartame-as- 
high-intensity-sweetener-of-choice-in-global-new-productlaunches-in-2017.

3. A. Talevi, Beneficial Effects of Stevia rebaudiana Bertoni and Steviol-Related Compounds on Health, In Sweeteners, J.M. Mérillon, K. G. Ramawat (Ed.s), Springer, Cham: 2018; pp. 263-284.

4. Morita Kagaku Kogyo, About stevia, 2018. See at the URL: www.morita-kagaku-kogyo.co.jp/main/html/e/stevia/

5. EFSA Panel on Food Additives and Nutrient Sources, Scientific Opinion on the safety of steviol glycosides for the proposed uses as a food additive, EFSA Journal 2010, 8 (4): 1537

6. J. E. Brandle, A. N. Starratt, M. Gijzen, Stevia rebaudiana: Its agricultural, biological, and chemical properties, Can. J. Plant Sci. 1998, 78, 527-536.

7. M. Ashwell, Stevia, Nature's Zero-Calorie Sustainable Sweetener, Nutr Today 2015, 50, 129-134.

8. J. Sepúlveda, R. Pinto, R. Garcés, J. Antileo, C.Gómez, D. Muñoz, D. García, C. Fuentealba, Use of Stevia rebaudiana purified extract as a sweetener on pediatric oral formulations, Int. J. Pharm. 2018, 536, 518-519.

9. P. Samuel, K. T Ayoob, B. A Magnuson, U. WölwerRieck, P. Bendix Jeppesen, P. J. Rogers, I. Rowland, R. Mathews, Stevia Leaf to Stevia Sweetener: Exploring Its Science, Benefits, and Future Potential, J. Nutr. 2018, 148, 1186S-1205S.

10. S. Stoyanova, J. Geuns, E. Hideg, W. Van den Ende, The food additives inulin and stevioside counteract oxidative stress, Int. J. Food Sci. Nutr. 2011, 62, 207-214.

11. H. Akashi, Y Yokoyama, Dried leaf extracts of stevia. Toxicological test, Shokuhin Kogyo 1975, 18, 34-43.

12. M. Okumura, Y. Fujita, M. Imamura, K. Aikawa, Studies on the safety of stevioside with rec-assay and reversion test, $J$. Food Hyg. Soc. Jpn. 1978, 19, 486-490.

13. J. M. C. Geuns, Safety evaluation of Stevia and stevioside, Studies in Natural Products Chemistry In Bioactive Natural Products (Part H), A.-u. Rahman (Ed.), Elsevier, Amsterdam: 2002; pp. 299-319.

14. For example, the "Go4Stevia" research project, 20132016. See at the URL: https://go4stevia.uni-hohenheim.de/

15. J. Halliday, Two global stevia trade associations launched this week, FoodNavigator, 6 October 2010. www.foodnavigator.com/Article/2010/10/06/Two-globalstevia-trade-associations-launched-this-week.

16. For example, the Symposium Stevia Leaf to Stevia Sweetener: Exploring Its Science, Benefits, and Future Potential, Chicago, 22 April 2017, at Experimental Biology 2017, American Society for Nutrition Scientific Sessions, Chicago, 22-26 April 2017.

17. Y.-L. McFarland (Frost \&Sullivan), The NutriCosmetics Market: A Global Health \& Wellness Megatrend, NutriCosmetic Summit 2011, Las Vegas, 22-23 June 2011.

18. S. Ceunen, J. M. C. Geuns, Steviol Glycosides: Chemical Diversity, Metabolism, and Function, J. Nat. Prod. 2013, 76, 1201-1228.

19. EFSA Panel on Food Additives and Nutrient Sources Added to Food, Scientific opinion on the safety of the proposed amendment of the specifications for steviol glycosides (E 960) as a food additive, EFSA J. 2015, 13 (12):4316,

20. M. Bridel, R. Lavieille, The sweet principle in Kaa-he-e (Stevia rebaudiana. Bertoni). II. Hydrolysis of stevioside by enzymes. III. Steviol by enzymic hydrolysis and isosteviol by acid hydrolysis, Bull. Soc. Chim. Biol. 1931, 13, 781-796.
21. F. Dolder, H. Lichti, E. Mosettig, P. Quitt, The structure and stereochemistry of steviol and isosteviol, J. Am. Chem. Soc. 1960, 82, 246-247.

22. Joint FAO WHO Expert Committee on Food Additives, 7. M. 2. Steviol glycosides, FAO JECFA monographs: Compendium of food additive specifications, Vol. 10, FAO (2010), pp. 17-21.

23. B. F. Zimmermann, Beaming steviol glycoside analysis into the next dimension, Food Chem. 2018, 241, 150-153.

24. W. H. Perera, T. Ramsaroop, R. Carvalho, D. L. Rodenburg, J. D. McChesney, A silica gel orthogonal highperformance liquid chromatography method for the analyses of steviol glycosides: novel tetra-glucopyranosyl steviol, Nat. Prod. Res. DOI: 10.1080/14786419.2018.1478826

25. A. B. Guerrero, L. San Emeterio, I. Domeño, I. Irigoyen, J. Muro, Steviol Glycoside Content Dynamics during the Growth Cycle of Stevia rebaudiana Bert, Am. J. Plant Sci. 2018, 9, 892-901.

26. D. Bursać Kovačević, M. Marasa Francisco, J. Barba, D. Granato, S. Roohinejadde, K. Mallikarjun, D. Montesano, J. M. Lorenzo, P. Putnik, Innovative technologies for the recovery of phytochemicals from Stevia rebaudiana Bertoni leaves: A review, Food Chem. 2018, 268, 513-521.

27. M. Formigoni, P. G. Milani, A. da Silva Avíncola, V. J. dos Santo, L. Benossi, A. S. Dacome, E. J. Pilau, S. Claudio da Costaa, Pretreatment with ethanol as an alternative to improve steviol glycosides extraction and purification from a new variety of stevia, Food Chem. 2018, 241, 452-459.

28. I. Laguta, O. Stavinskaya, O. Kazakova, T. Fesenko S. Brychka, Green synthesis of silver nanoparticles using Stevia leaves extracts, Appl. Nanosci. 2018, DOI: 10.1007/s13204018-0680-5.

29. L. Bandy, E960: Stevia May Be an Additive but Its Natural Sourcing Will Make It a Winner, Euromonitor International, $\quad 11 \quad$ February 2013. https://blog.euromonitor.com/2013/02/e960-stevia-may-be-anadditive-but-its-natural-sourcing-will-make-it-a-winner.html

30. M. Pagliaro, Pectin Production and Global Market, Agro Food Industry Hi Tech 2016, 27, 17-20.

31. Grand View Research, Stevia Market Size, Share \& Trends Analysis Report By Application (Beverages, Food, Pharmaceutical, Tabletop Sweeteners), By Region (North America, APAC, Europe, MEA, Latin America), And Segment Forecasts, 2018 - 2024, San Francisco: July 2018.

32. Zion Market Research, Stevia Market by Extract Type (Liquid, Powder, and Leaf) and by Application (Dairy Products, Bakery and Confectionery Products, Dietary Supplements, Packaged Food Products, Beverages, and Others): Global Industry Perspective, Comprehensive Analysis and Forecast, 2018 - 2024, Pune: June 2018.

33. Mintel Global New Products Database, Global food and beverage products with stevia: 2011-2016 data, 2017. See ath URL: www.mintel.com/global-new-products-database.

34. International Stevia Council, Industry data report, Brussels, 2017.

35. 'Rize sugar': Çaykur, Chinese partners to produce stevia in Turkey, Daily Sabah, 11 August 2017.

36. Joint FAO WHO Expert Committee on Food Additives, Safety evaluation of certain food additives. Steviol Glycosides (addendum), WHO Food Additive Series, 60, Geneva: 2009.

37. R. S. McQuate, Ensuring the Safety of Sweeteners From Stevia, Food Technology 2011, 65, 42-49.

38. M. Sosnowska, Stevia - Too Good To Be True?, Spend Matters, 24 November 2014. See at the URL: 
http://spendmatters.com/2014/11/24/stevia-too-good-to-be-

true/

39. R. J. Whitehead, High stevia volumes predicted despite low price and limited production, FOOD-Navigator Asia, 2 May 2017. See at the URL: www.foodnavigatorasia.com/Article/2017/05/02/High-stevia-volumes-predicteddespite-low-price-and-limited-production

40. N. H. Kamarulzaman, K. Jamal, G. Vijayan, S. Munirah Ab. Jalil, Will Consumers Purchase Stevia as a Sugar Substitute?: An Exploratory Study on Consumer Acceptance, J. Food Prod. Market. 2014, 20 (sup1), 122-139.

41. A. Douglas Kinghorn, Stevia Rebaudiana Safety Review incorporated into: GRAS Affirmation Petition, Stevia leaves, presented to the US Food and Drug Administration on behalf of the American Herbal Products Association, April 23, 1992.

42. C. de la Peña, Artificial sweetener as a historical window to culturally situated health, Ann. N.Y. Acad. Sci. 2010, 1190, 159-165.

43. The Stevial consortium. See at the URL: www.stevial.eu/en/

44. K. Mizutani, O. Tanaka, Use of Stevia rebaudiana sweeteners in Japan In Stevia: The Genus Stevia, A. Douglas Kinghorn (Ed.), Taylor and Francis, London: 2002; pp. 178196.

45. Sabeera Ali, Food Industry Asia, cit. in C. Tay, 'Inaccurate' information about sweeteners hindering diabetes and obesity progress in Southeast Asia, FOODNavigator Asia, 2 April 2018. See at the URL: www.foodnavigatorasia.com/Article/2018/04/02/Inaccurate-information-aboutsweeteners-hindering-diabetes-and-obesity-progress-inSoutheast-Asia

46. X. E. Li, K. Lopetcharat, M. A. Drake, Parents' and children's acceptance of skim chocolate milks sweetened by monk fruit and stevia leaf extracts, J. Food Sci. 2015, 80, S1083-92.

47. K. Ayoob, The State of the Science on Stevia, International Congress of Nutrition, Buenos Aires, October 15-20, 2017.

48. M. Belović, A. Torbica, I. Pajić-Lijaković, J. Mastilović, Development of low calorie jams with increased content of natural dietary fibre made from tomato pomace, Food Chem. 2017, 237, 1226-1233.

49. G. Taubes, What if sugar is worse than just empty calories? An essay by Gary Taubes, BMJ 2018, 360:j5808. 